\title{
Reappraising the spectrum of bleeding gastrointestinal angioectasia in a degenerative calcific aortic valve stenosis: Heyde's syndrome
}

\author{
Nelson Musilanga ${ }^{1,2^{*}}$ (D), Zhou Hongli ${ }^{3}$ and Cai Hongyu ${ }^{4}$
}

\begin{abstract}
Background: The occurrence of bleeding gastrointestinal angioectasia in elderly patients with degenerative calcific aortic stenosis is one of the most challenging clinical scenarios. A number of studies have shown that this clinical phenomenon is known as Heyde's syndrome.

Main body of the abstract: The pathogenesis of Heyde's syndrome is mainly due to the loss of high-molecularweight von Willebrand factor (HMW VWF) multimers, as a consequent fragmentation of HMW vWF multimers as they pass through the stenosed aortic valve leading to acquired von Willebrand syndrome type IIA. Aortic valve replacement has proven to be a more effective management approach in the cessation of recurrent episodes of gastrointestinal bleeding.

Short conclusion: Physicians should have a high index of suspicion when dealing with elderly patients with established aortic stenosis presenting with iron deficiency anemia or unclear gastrointestinal bleeding. Parallel consultations between different specialties are essential for appropriate management.
\end{abstract}

Keywords: Aortic valve stenosis, Heyde's syndrome, Angioectasia, Angiodysplasia, Gastrointestinal hemorrhage

\section{Background} Heyde's syndrome

Heyde's syndrome (HS) is a rare clinicopathological syndrome first described by Edward Heyde, as an association of gastrointestinal bleeding and a degenerative calcific aortic valve stenosis. Dr. Heyde gave a report of 10 patients in 1958 with classic signs of calcific aortic valve stenosis, with harsh systolic murmur radiating widely into the neck or back, had massive gastrointestinal bleeding for which he could not establish the cause [1].

\footnotetext{
* Correspondence: nmusilanga@gmail.com

${ }^{1}$ Internal Medicine, First Affiliated Hospital Of Jinzhou Medical University, Jinzhou, China

${ }^{2}$ Internal Medicine, Muhimbili National Hospital-Mloganzila, Dar es Salaam, Tanzania

Full list of author information is available at the end of the article
}

In subsequent decades, HS has been further studied to fully reinforce the exact pathological mechanism [2-4], eventually leading to the discovery of hemostatic disorder, acquired von Willebrand syndrome type IIA (vWS-IIA), as a potential predisposing factor to patients with otherwise clinically silent gastrointestinal angioectasia to bleed $[5,6]$.

Despite a debate surrounding the actual definition of HS, many authors agree that it refers to a clinical syndrome comprising a triad of degenerative calcific aortic valve stenosis, acquired von Willebrand syndrome, and recurrent bleeding gastrointestinal angioectasia $[7,8]$.

This article aims at giving an updated review of studies that explored the clinical association between these conditions, its prevalence, and accurate diagnosis and proper management of the syndrome.

SpringerOpen

(c) The Author(s). 2021 Open Access This article is licensed under a Creative Commons Attribution 4.0 International License, which permits use, sharing, adaptation, distribution and reproduction in any medium or format, as long as you give appropriate credit to the original author(s) and the source, provide a link to the Creative Commons licence, and indicate if changes were made. The images or other third party material in this article are included in the article's Creative Commons licence, unless indicated otherwise in a credit line to the material. If material is not included in the article's Creative Commons licence and your intended use is not permitted by statutory regulation or exceeds the permitted use, you will need to obtain permission directly from the copyright holder. To view a copy of this licence, visit http://creativecommons.org/licenses/by/4.0/. 


\section{Aortic stenosis}

Aortic stenosis is the most common valvular heart disease, frequently caused by calcification of the aortic valve leaflets $[9,10]$. Several studies in developing countries have reported the prevalence of aortic stenosis progressively increases with age ranging from as low as $0.02 \%$ in patients aged $18-44$ years to as high as $9.8 \%$ in patients in the eighth decade of life [11-13]. Consequently, aortic stenosis is one of the most common causes of morbidity and mortality in older patients [14].

The pathobiology of calcific aortic stenosis is not only explained by aging but also involves a dynamic inflammatory process of endothelial damage due to lipid accumulation, oxidative stress, angiogenesis, and genetic factors leading to fibrosis, valve leaflets thickening, and, ultimately, calcification $[15,16]$. Calcific aortic valve stenosis causes increased leaflet stiffness and a narrowed aortic valve opening that results in a pressure gradient across the valve $[17,18]$.

It is important to note that progressive aortic valve narrowing with coexistent left ventricular pressure overload and subsequently left ventricular hypertrophy may transition to heart failure and development of symptoms [19].

\section{Angioectasia}

Angioectasia is the most common vascular lesion in the gastrointestinal tract. They can be found throughout the gastrointestinal tract, with the most common site being the cecum and ascending colon [20]. They are characterized by dilated, ectatic, tortuous thin-walled vessels of the gastrointestinal tract mucosa or submucosa-including the arterioles, capillaries, and venules without inflammation or fibrosis [21, 22].

Angioectasia is often associated with advanced age, and their clinical presentation varies from being an asymptomatic incidental finding to a life-threatening severe gastrointestinal bleeding [23]. Its prevalence is estimated to be $0.8-6.2 \%$ [24] and accounting for up to $40 \%$ of colonic bleeding lesions [20].

The pathogenesis of angioectasia is not fully elucidated; however, numerous hypotheses have been proposed including one which suggests angioectatic lesions develop with aging due to chronic low-grade intermittent obstruction of the submucosa venules as a result of increased contractility at the level of the muscularis propria, consequently leading to congestion of the capillaries and failure of the pre-capillary sphincters, mucosa ischemia, and eventually formation of small arteriovenous collaterals (neovascularization) [20]. Furthermore, angiogenesis factors such as vascular endothelial growth factors (VEGF) and deficiency in von Willebrand factor (vWF) have also been implicated to play an active role in the pathogenesis $[25,26]$.

\section{Main text}

Correlation between aortic stenosis and angioectasia

Several authors have encountered a challenge in proving the statistical causal link between aortic stenosis and gastrointestinal angioectasia. This is mainly attributed to individual study methodological shortcomings [27]. Given the circumstance that both conditions are predominantly due to chronic degenerative processes, consequently, they may as well coexist in older patients.

Some studies have reported no significant association between aortic stenosis and angioectasia. A study that evaluated echocardiographic findings of 29 patients with angioectasia found out none had evidence of aortic stenosis [28]. Furthermore, Bhutani et al. conducted a prospective case-control study of 40 patients with gastrointestinal angioectasia detected by endoscopy and reported no increased prevalence of aortic stenosis [29].

However, the most recent clinical observations had shown the association between calcific aortic stenosis and gastrointestinal bleeding secondary to angioectasia. Table 1 summarizes the results of some of the most detailed studies.

\section{Pathophysiology}

There are several conceivable explanation for the pathogenesis of HS. However, the deficiency of highmolecular-weight (HMW) multimer of vWF is the most plausible link between degenerative calcific aortic valve stenosis and bleeding gastrointestinal angioectasia [5, 33]. HMW vWF multimers play a major role in the hemostatic function of the compromised blood vessels, i.e., gastrointestinal angioectatic vessels through mediating the platelet-subendothelial adhesion and inducing the platelet-platelet aggregation [34].

In HS, however, these HMW vWF multimers passing through a stenosed aortic valve are subjected to high mechanical shear stress leading to fragmentation as a result of elevated vWF protease activity-disintegrin and metalloprotease mediated by thrombospondin-type motif, member 13 (ADAMTS13). This leads to acquired von Willebrand's disease (vWD) [35-37]. Therefore, reduced levels of circulating HMW vWF multimers impair plateletmediated hemostasis in the gastrointestinal angioectatic vessels hence predispose patients to bleeding [38].

\section{Diagnosis}

The diagnosis of Heyde's syndrome is common in elderly individuals with structural heart disease who present with a recent history of unexplained episodes of lower gastrointestinal bleeding [39, 40]. Moreover, it can present with unexplained recurrent iron deficiency anemia in patients with established aortic stenosis [41]. Therefore, it is imperative to have a high degree of 
Table 1 Studies evaluating the association between angioectasia and aortic stenosis

\begin{tabular}{|c|c|c|c|}
\hline Source & Study design & $\begin{array}{l}\text { Number of } \\
\text { participants } \\
\text { or events }\end{array}$ & Summary of findings \\
\hline Batur et al. [30] 2003, USA & Retrospective study & 92,075 & $\begin{array}{l}\text { 2.3-fold increase in the prevalence of AS of any severity in patients with Gl } \\
\text { AVMs compared with the general population }[31.7 \%, 14.0 \% ; P<0.001] \\
4.1 \text {-fold increase in severe AS in the AVMs group compared with the genera } \\
\text { population }[14.3 \% \text { vs } 3.5 \% ; P<0.001]\end{array}$ \\
\hline Pate et al. [31] 2004, Canada & Retrospective study & $3,800,000$ & $\begin{array}{l}\text { Significant association } P<0.0001 \text { between aortic stenosis and bleeding } \\
\text { gastrointestinal angioectasia with an odds ratio of } 4.5(95 \% \text { Cl 3.0-6.8) }\end{array}$ \\
\hline Jehangir et al. [32] 2018, USA & Retrospective study & 32,079 & $\begin{array}{l}7.02 \% \text { prevalence of aortic valve disease in patients with bleeding intestinal } \\
\text { angioectasia } \\
\text { Adjusted odds ratio still reveals significant association (odds ratio }=2.37 \text {, } \\
95 \% \mathrm{Cl} 2.10-2.66, P<0.001 \text { ). }\end{array}$ \\
\hline
\end{tabular}

AS aortic stenosis, GI gastrointestinal, AVMs arteriovenous malformations

suspicion in these patients, especially if they have concomitant aortic stenosis and gastrointestinal bleeding.

A typical sign in keeping with aortic stenosis is the presence of systolic murmur at the second right intercostal space with radiation toward the right carotid artery which should be confirmed with an echocardiogram. Gastrointestinal angioectasia may be diagnosed by endoscopic imaging or radiographic imaging depending on the clinical scenario and severity of bleeding [20].

There are various tests that have been developed for screening and diagnosing von Willebrand disease. Unfortunately, there is no single assay that can diagnose vWD with complete confidence. vWF antigen activity (vWF:Ag) assays quantify the plasma vWF protein levels, VWF ristocetin cofactor activity (VWF:RCo) most commonly used to assess the binding capacity of vWF to platelet glycoprotein Ib $\alpha$ (GPIb $\alpha)$, and VWF collagen binding (VWF:CB) which assesses binding of vWF to the platelet collagen receptor. A decreased VWF:RCo/VWF: $\mathrm{Ag}$ is indicative of either absence or lack of highmolecular-weight multimer levels. Therefore, a confirmatory test of VWF multimer distribution should be performed using gel electrophoresis [42, 43].

However, although HS is developing as a common clinical entity, the initial diagnostic workup should target to explore more common causes of gastrointestinal bleeding, including gastric or duodenal ulcer, gastrointestinal malignancy, and inflammatory bowel disease.

\section{Treatment}

Due to the complexity nature of Heyde's syndrome, the optimal management strategy should be tailored on a patient-by-patient basis and often times requiring a multidisciplinary approach. There is inadequate evidence from prospective randomized controlled trials evaluating the management of HS. Therefore, most of the available data on treatment are based on case reports.

\section{Aortic valve replacement}

Expert consensus recommends aortic valve replacement (AVR) as the first-line treatment in the management of Heyde's syndrome [4, 44]. It reduces the mechanical shear stress on the HMW vWF multimers inhibiting their cleavage by ADAMTS13 and consequently improves coagulation abnormalities implicated in Heyde's syndrome. There are several observational studies that have demonstrated potential therapeutic benefits of AVR [45-53]. All studies were published between 2010 and 2020; cessation of gastrointestinal bleeding following AVR was the most measured outcome. The authors reported no further episodes of gastrointestinal bleeding with normalization of HMW vWF multimer as summarized in Table 2. Although these findings were not replicated in a few case reports [54, 55], most of the evidence available in the literature has proven AVR to be more effective.

\section{Pharmacological therapies}

There are various medical therapies that have been used to lessen episodes of bleeding from gastrointestinal angioectasia, including hormonal therapy, octreotide, and thalidomide. Octreotide, a somatostatin analog, is considered to inhibit angiogenesis by downregulation of VEGF and has demonstrated a significant therapeutic benefit [56]. In an open-label, randomized controlled trial including 55 patients assessing the treatment response of thalidomide in reducing bleeding episodes, Ge et al. [57] confirmed a significantly higher response rate in the treatment group $71 \%$ compared with iron-controlled group $4 \%$. Junquera et al. noted a slight beneficial effect of combined estrogen and progesterone therapy in the management of bleeding angioectasia [58]. It is important to note that patients' clinical improvements observed in medical therapy are usually temporary as this approach does not address the primary pathophysiological mechanism of Heyde's syndrome. 
Table 2 Studies assessing the effectiveness of AVR in patients with Heyde's syndrome

\begin{tabular}{llll}
\hline Study & Age (years) & Follow-up & Summary of findings \\
\hline Mirna et al. [45] 2019, Austria & 73 & 3 months & Normal quantity of vWF multimers, normal Hb concentration \\
Ramachandran et al. [46] 2018, USA & 85 & 6 months & No need for blood transfusion with a normal Hb concentration \\
Alshuwaykh et al. [47] 2018, USA & 56 & 6 months & No further episodes of Gl bleeding \\
lijima et al. [48] 2018, Japan & 77 & 20 months & Cessation of recurrent Gl bleeding \\
Shibamoto et al. [49] 2017, Japan & 87 & 20 months & No episodes of Gl bleeding and no need for blood transfusion \\
Balbo et al. [50] 2017, Brazil & 81 & 6 months & No episodes of recurring Gl bleeding \\
Benton et al. [51] 2014, USA & 77 & 10 months & Normal levels of HMW vWF multimers and free from recurrent Gl bleeding \\
Saad et al. [52] 2013, UK & 76 & 4 months & Free from iron deficiency anemia \\
Pyxaras et al. [53] 2012, Italy & 89 & 6 months & Normal hematological parameters with no episodes of Gl bleeding \\
\hline
\end{tabular}

vWF von Willebrand factor, $H b$ hemoglobin, $H M W$ high molecular weight, Gl gastrointestinal

\section{Endoscopic therapies}

This is generally challenging, particularly in a setting of multiple gastrointestinal angioectatic lesions. Nevertheless, it can be used as a bridge therapy to AVR or in patients considered unfit for AVR [59]. Several endoscopic options for the management of bleeding gastrointestinal lesions been have evaluated for safety, efficacy, and longterm outcomes. In a prospective cohort study of $100 \mathrm{pa}$ tients, the long-term outcome of the argon plasma coagulation (APC) method was evaluated [60]. In which, bleeding resolved in $85 \%$ of patients after a median follow-up of 20 months. Transfusion requirements ceased in $90 \%$ of patients, and a statistically significant increase in the mean hemoglobin levels was observed. The endoscopic clip technique has been shown to be useful in cases of isolated and relatively large bleeding colonic lesions [61]. Other beneficial approaches include photocoagulations (laser) and endoscopic multiband ligation, while electrocoagulation technique is not currently recommended due to its relatively higher rates of re-bleeding. Endoscopic procedure-related complications including perforation have also been reported in several studies [62, 63].

\section{Bowel resection}

Emergency bowel resection can be employed in selected cases of an acute, severe localized area of bleeding refractory to other treatment options. It is often considered curative [20], but accurate localization of bleeding lesion is crucial in order to avoid bleeding recurrence from a missed angioectatic lesion located elsewhere in the gastrointestinal tract [64]. It is important to note, however, this option may not be suitable in most cases as it carries a higher risk of excessive bleeding secondary to coagulopathy.

\section{Superselective transcatheter arterial embolization}

Superselective arterial embolization uses embolic agents such as gelfoam, microcoils, and n-butyl cyanoacrylate to occlude the bleeding vessel in a gastrointestinal angioectasia. This technique has been shown to be successful in the management of bleeding angioectasia [65]. A systematic review reported a number of procedurerelated complications such as bowel infarction, arterial dissections, and hematomas [66].

\section{Conclusions}

Heyde's syndrome is developing as a common and significant clinical entity, particularly among elderly patients with significant aortic stenosis. Therefore, physicians are recommended to have a high index of suspicion when dealing with elderly patients with established aortic stenosis presenting with iron deficiency anemia or unclear gastrointestinal bleeding. Parallel consultations between different specialties are critical for appropriate diagnosis and treatment approach, although current evidence suggests aortic valve replacement should be considered in most cases. In hemodynamically unstable patients with a high risk of complications from a more invasive therapy, a conservative management with oral iron supplements and regular transfusions with packed red blood cells is beneficial.

\section{Abbreviations \\ AVR: Aortic valve replacement; AVMs: Arteriovenous malformations; HS: Heyde's syndrome; HMW: High molecular weight; VWD: von Willebrand disease; vWF: von Willebrand factor; vWS-IIA: von Willebrand syndrome type IIA; VEGF: Vascular endothelial growth factor}

\section{Acknowledgements}

Not applicable

\section{Authors' contributions}

NM has made a substantial contribution to the conception of the idea, relevant literature search, and discussion of the article's contents and wrote the initial manuscript draft. $\mathrm{ZH}$ and $\mathrm{CH}$ made substantial contributions to the discussion of the article's content and improving the initial manuscript draft. All authors have read and approved the final manuscript for submission.

Funding

The authors received no funding. 


\section{Availability of data and materials}

Not applicable

\section{Declarations}

Ethics approval and consent to participate

Not applicable

\section{Consent for publication}

Not applicable

\section{Competing interests}

The authors declare that they have no competing interests.

\section{Author details}

'Internal Medicine, First Affiliated Hospital Of Jinzhou Medical University, Jinzhou, China. ${ }^{2}$ Internal Medicine, Muhimbili National Hospital-Mloganzila, Dar es Salaam, Tanzania. Internal Medicine-Nephrology Division, First Affiliated Hospital Of Jinzhou Medical University, Jinzhou, China. ${ }^{4}$ Internal Medicine-Cardiology Division, First Affiliated Hospital Of Jinzhou Medical University, Jinzhou, China.

Received: 18 January 2021 Accepted: 26 April 2021

Published online: 25 May 2021

\section{References}

1. Heyde EC (1958) Gastrointestinal bleeding in aortic stenosis. N Engl J Med 259(4):196-196. https://doi.org/10.1056/nejm195807242590416

2. Gelfand ML, Cohen T, Ackert JJ, Ambos M, Mayadag M (1979) Gastrointestinal bleeding in aortic stenosis. Am J Gastroenterol 71(1):30-38

3. Greenstein RJ, McElhinney AJ, Reuben D, Greenstein AJ (1986) Colonic vascular ectasias and aortic stenosis: coincidence or causal relationship? Am J Surg 151(3):347-351. https://doi.org/10.1016/0002-9610(86)90465-4

4. King RM, Pluth JR, Giuliani ER (1987) The association of unexplained gastrointestinal bleeding with calcific aortic stenosis. Ann Thorac Surg 44(5): 514-516. https://doi.org/10.1016/s0003-4975(10)62112-1

5. Warkentin TE, Moore JC, Anand SS, Lonn EM, Morgan DG (2003) Gastrointestinal bleeding, angiodysplasia, cardiovascular disease, and acquired von Willebrand syndrome. Transfus Med Rev 17(4):272-286. https://doi.org/10.1016/s0887-7963(03)00037-3

6. Loscalzo J (2012) From clinical observation to mechanism--Heyde's syndrome. N Engl J Med 367(20):1954-1956. https://doi.org/10.1056/ NEJMcibr1205363

7. Massyn MW, Khan SA (2009) Heyde syndrome: a common diagnosis in older patients with severe aortic stenosis. Age Ageing 38(3):267-270; discussion 251. https://doi.org/10.1093/ageing/afp019

8. Theis SR, Turner SD (2020) Heyde syndrome. StatPearls Publishing, Treasure Island (FL)

9. Berglund V, Mattsson G, Magnusson P (2018) [Aortic stenosis is a common disease which requires individualized treatment]. Lakartidningen 115:E3DR

10. Toutouzas K, Stathogiannis K, Latsios G, Synetos A, Drakopoulou M, Penesopoulou V, Michelongona A, Tsiamis E, Tousoulis D (2019) Biomarkers in aortic valve stenosis and their clinical significance in transcatheter aortic valve implantation. Curr Med Chem 26(5):864-872. https://doi.org/10.2174/ 0929867324666170727110241

11. Eveborn GW, Schirmer H, Heggelund G, Lunde P, Rasmussen K (2013) The evolving epidemiology of valvular aortic stenosis. The Tromsø Study. Heart 99:396 LP-396400. https://doi.org/10.1136/heartjil-2012-302265

12. Thaden JJ, Nkomo VT, Enriquez-Sarano M (2014) The global burden of aortic stenosis. Prog Cardiovasc Dis 56(6):565-571. https://doi.org/10.1016/j.pcad.2 014.02 .006

13. Lindman BR, Clavel M-A, Mathieu P, lung B, Lancellotti P, Otto CM, Pibarot P (2016) Calcific aortic stenosis. Nat Rev Dis Prim 2(1):16006. https://doi.org/1 $0.1038 /$ nrdp. 2016.6

14. Lindman BR, Patel JN (2016) Multimorbidity in older adults with aortic stenosis. Clin Geriatr Med 32(2):305-314. https://doi.org/10.1016/j.cger.2016. 01.006

15. Thanassoulis G, Campbell CY, Owens DS, Smith JG, Smith AV, Peloso GM, Kerr KF, Pechlivanis S, Budoff MJ, Harris TB, Malhotra R, O'Brien KD, Kamstrup PR, Nordestgaard BG, Tybjaerg-Hansen A, Allison MA, Aspelund T, Criqui MH, Heckbert SR, Hwang SJ, Liu Y, Sjogren M, van der Pals J, Kälsch H,
Mühleisen TW, Nöthen MM, Cupples LA, Caslake M, di Angelantonio E, Danesh J, Rotter Jl, Sigurdsson S, Wong Q, Erbel R, Kathiresan S, Melander O, Gudnason V, O'Donnell CJ, Post WS, CHARGE Extracoronary Calcium Working Group (2013) Genetic associations with valvular calcification and aortic stenosis. N Engl J Med 368(6):503-512. https://doi.org/10.1056/ NEJMoa1109034

16. Akahori H, Tsujino T, Masuyama T, Ishihara M (2018) Mechanisms of aortic stenosis. J Cardiol 71(3):215-220. https://doi.org/10.1016/j.jjcc.2017.11.007

17. Dweck MR, Boon NA, Newby DE (2012) Calcific aortic stenosis: a disease of the valve and the myocardium. J Am Coll Cardiol 60(19):1854-1863. https:// doi.org/10.1016/j.jacc.2012.02.093

18. Kamperidis $\mathrm{V}$, van Rosendael PJ, Katsanos $\mathrm{S}$, van der Kley F, Regeer M, al Amri I, Sianos G, Marsan NA, Delgado V, Bax JJ (2015) Low gradient severe aortic stenosis with preserved ejection fraction: reclassification of severity by fusion of Doppler and computed tomographic data. Eur Heart J 36(31): 2087-2096. https://doi.org/10.1093/eurheartj/ehv188

19. Zheng KH, Tzolos E, Dweck MR (2020) Pathophysiology of aortic stenosis and future perspectives for medical therapy. Cardiol Clin 38(1):1-12. https:// doi.org/10.1016/j.ccl.2019.09.010

20. Sami SS, Al-Araji SA, Ragunath K (2014) Review article: gastrointestinal angiodysplasia - pathogenesis, diagnosis and management. Aliment Pharmacol Ther 39(1):15-34. https://doi.org/10.1111/apt.12527

21. Regula J, Wronska E, Pachlewski J (2008) Vascular lesions of the gastrointestinal tract. Best Pract Res Clin Gastroenterol 22(2):313-328. https://doi.org/10.1016/j.bpg.2007.10.026

22. DeBenedet AT, Saini SD, Takami M, Fisher LR (2011) Do clinical characteristics predict the presence of small bowel angioectasias on capsule endoscopy? Dig Dis Sci 56(6):1776-1781. https://doi.org/10.1007/s10620-01 $0-1506-9$

23. Tsai Y-Y, Chen B-C, Chou Y-C, Lin JC, Lin HH, Huang HH, Huang TY (2019) Clinical characteristics and risk factors of active bleeding in colonic angiodysplasia among the Taiwanese. J Formos Med Assoc 118(5):876-882. https://doi.org/10.1016/j.jfma.2018.10.001

24. Foutch PG, Rex DK, Lieberman DA (1995) Prevalence and natural history of colonic angiodysplasia among healthy asymptomatic people. Am J Gastroenterol 90(4):564-567

25. Chen H-M, Ge Z-Z, Liu W-Z, Lu H, Xu CH, Fang JY, Xiao SD (2009) The mechanisms of thalidomide in treatment of angiodysplasia due to hypoxia. Zhonghua nei ke za zhi 48(4):295-298

26. Starke RD, Ferraro F, Paschalaki KE, Dryden NH, McKinnon TAJ, Sutton RE, Payne EM, Haskard DO, Hughes AD, Cutler DF, Laffan MA, Randi AM (2011) Endothelial von Willebrand factor regulates angiogenesis. Blood 117(3): 1071-1080. https://doi.org/10.1182/blood-2010-01-264507

27. Imperiale TF, Ransohoff DF (1988) Aortic stenosis, idiopathic gastrointestinal bleeding, and angiodysplasia: is there an association? A methodologic critique of the literature. Gastroenterology 95(6):1670-1676. https://doi.org/1 0.1016/s0016-5085(88)80095-7

28. Mehta PM, Heinsimer JA, Bryg RJ, Jaszewski R, Wynne J (1989) Reassessment of the association between gastrointestinal arteriovenous malformations and aortic stenosis. Am J Med 86(3):275-277. https://doi.org/10.1016/00029343(89)90295-7

29. Bhutani MS, Gupta SC, Markert RJ, Barde CJ, Donese R, Gopalswamy N (1995) A prospective controlled evaluation of endoscopic detection of angiodysplasia and its association with aortic valve disease. Gastrointest Endosc 42(5):398-402. https://doi.org/10.1016/s0016-5107(95)70038-2

30. Batur P, Stewart WJ, Isaacson JH (2003) Increased prevalence of aortic stenosis in patients with arteriovenous malformations of the gastrointestinal tract in Heyde syndrome. Arch Intern Med 163(15):1821-1824. https://doi. org/10.1001/archinte.163.15.1821

31. Pate GE, Mulligan A (2004) An epidemiological study of Heyde's syndrome: an association between aortic stenosis and gastrointestinal bleeding. J Heart Valve Dis 13(5):713-716

32. Jehangir A, Pathak R, Ukaigwe A, Donato AA (2018) Association of aortic valve disease with intestinal angioectasia: data from the Nationwide Inpatient Sample. Eur J Gastroenterol Hepatol 30(4):438-441. https://doi. org/10.1097/MEG.0000000000001068

33. Natorska J, Bykowska K, Hlawaty M, Marek G, Sadowski J, Undas A (2011) Increased thrombin generation and platelet activation are associated with deficiency in high molecular weight multimers of von Willebrand factor in patients with moderate-to-severe aortic stenosis. Heart 97(24):2023-2028. https://doi.org/10.1136/hrt.2010.217273 
34. Flood VH (2014) Perils, problems, and progress in laboratory diagnosis of von Willebrand disease. Semin Thromb Hemost 40(01):41-48. https://doi. org/10.1055/s-0033-1363166

35. Yoshida K, Tobe S, Kawata M, Yamaguchi M (2006) Acquired and reversible von Willebrand disease with high shear stress aortic valve stenosis. Ann Thorac Surg 81(2):490-494. https://doi.org/10.1016/j.athoracsur.2005.07.074

36. Casonato A, Sponga S, Pontara E, Cattini MG, Basso C, Thiene G, Cella G, Daidone V, Gerosa G, Pagnan A (2011) von Willebrand factor abnormalities in aortic valve stenosis: pathophysiology and impact on bleeding. Thromb Haemost 106(07):58-66. https://doi.org/10.1160/TH10-10-0634

37. Tamura T, Horiuchi H, Imai M, Tada T, Shiomi H, Kuroda M, Nishimura S, Takahashi Y, Yoshikawa Y, Tsujimura A, Amano M, Hayama Y, Imamura S, Onishi N, Tamaki Y, Enomoto S, Miyake M, Kondo H, Kaitani K, Izumi C, Kimura T, Nakagawa Y (2015) Unexpectedly high prevalence of acquired von Willebrand syndrome in patients with severe aortic stenosis as evaluated with a novel large multimer index. J Atheroscler Thromb 22(11): 1115-1123. https://doi.org/10.5551/jat.30809

38. Panzer S, Badr Eslam R, Schneller A et al (2010) Loss of high-molecularweight von Willebrand factor multimers mainly affects platelet aggregation in patients with aortic stenosis. Thromb Haemost 103(02):408-414. https:// doi.org/10.1160/TH09-06-0391

39. Morishima A, Marui A, Shimamoto T, Saji Y, Tambara K, Nishina T, Komeda M (2007) Successful aortic valve replacement for Heyde syndrome with confirmed hematologic recovery. Ann Thorac Surg 83(1):287-288. https:// doi.org/10.1016/j.athoracsur.2006.05.082

40. Hudzik B, Wilczek K, Gasior M (2016) Heyde syndrome: gastrointestinal bleeding and aortic stenosis. Can Med Assoc J 188(2):135-138. https://doi. org/10.1503/cmaj.150194

41. Alsidawi S, Couto M, López-Candales A (2015) Acquired von Willebrand syndrome in aortic stenosis: case report and review. Bol Asoc Med P R 107(2):86-88

42. Roberts JC, Flood VH (2015) Laboratory diagnosis of von Willebrand disease Int J Lab Hematol 37(Suppl 1):11-17. https://doi.org/10.1111/ijlh.12345

43. Petricevic M, Knezevic J, Samoukovic G, Bradaric B, Safradin I, Mestrovic M, Papestiev V, Hodalin A, Madzar T, Mihalj M, Rotim A, Biocina B (2020) Diagnosis and management of acquired von Willebrand disease in heart disease: a review of the literature. Thorac Cardiovasc Surg 68(03):200-211. https://doi.org/10.1055/s-0038-1673670

44. Garcia LR, Garzesi AM, Tripoli G et al (2019) Heyde syndrome treated by conventional aortic valve replacement. Braz J Cardiovasc Surg 34:630-632

45. Mirna M, Lichtenauer M, Theurl T, Ausserwinkler M, Topf A, Westphal T, Gampenrieder SP, Pretsch I, Greil R, Hoppe UC (2019) Transcatheter aortic valve implantation in a patient with suspected hereditary von Willebrand disease and severe gastrointestinal bleeding - a case report. Scott Med J 64(4):142-147. https://doi.org/10.1177/0036933019862155

46. Ramachandran $\mathrm{R}$, Uqdah $\mathrm{H}$, Jani N (2018) A case of recurrent obscure gastrointestinal bleeding: Heyde's syndrome - case report and review. J Community Hosp Intern Med Perspect 8(3):127-129. https://doi.org/10.1 080/20009666.2018.1470441

47. Alshuwaykh O, Krier MJ (2018) A case of Heyde syndrome with resolution of gastrointestinal bleeding two weeks after aortic valve replacement. Am J Case Rep 19:924-926. https://doi.org/10.12659/AJCR.911298

48. lijima M, Itoh N, Murase R, Makino Y (2018) A surgical case of aortic stenosis with recurrent gastrointestinal bleeding: Heyde syndrome. Int J Surg Case Rep 53:281-284. https://doi.org/10.1016/j.ijscr.2018.10.078

49. Shibamoto A, Kawaratani H, Kubo T, Nishimura N, Sato S, Seki K, Sawada Y, Takaya H, Okura Y, Takeda K, Uejima M, Namisaki T, Moriya K, Mitoro A, Yamao J, Yoshiji H (2017) Aortic valve replacement for the management of Heyde syndrome: a case report. J Nippon Med Sch 84(4):193-197. https:// doi.org/10.1272/jnms.84.193

50. Balbo CP, Seabra LP, Galoro VG, Caputi G, Palma JH, Buffolo Ê (2017) Heyde's syndrome and transcatheter aortic valve implantation. Arq Bras Cardiol 108(4):378-380. https://doi.org/10.5935/abc.20160193

51. Benton SMJ, Kumar A, Crenshaw M, Fredi JL (2014) Effect of transcutaneous aortic valve implantation on the Heyde's syndrome. Am J Cardiol 114(6): 953-954. https://doi.org/10.1016/j.amjcard.2014.06.025

52. Saad RA, Lwaleed BA, Kazmi RS (2013) Gastrointestinal bleeding and aortic stenosis (Heyde syndrome): the role of aortic valve replacement. J Card Surg 28(4):414-416. https://doi.org/10.1111/jocs.12131

53. Pyxaras SA, Santangelo S, Perkan A, Vitrella G, Rakar S, Grazia ED, Salvi A, Sinagra G (2012) Reversal of angiodysplasia-derived anemia after transcatheter aortic valve implantation. J Cardiol Cases 5(2):e128-e131. https://doi.org/10.1016/j.jccase.2011.10.002

54. lquille J, Nader J, Colpart E, Caus T (2017) Unusual gastrointestinal bleeding after sutureless aortic valve replacement: a word of caution. Ann Thorac Surg 103(3):e225-e226. https://doi.org/10.1016/j.athoracsur.2016.08.073

55. Akutagawa T, Shindo T, Yamanouchi K, Hayakawa M, Ureshino H, Tsuruoka N, Sakata Y, Shimoda R, Noguchi R, Furukawa K, Morita S, Iwakiri R, Kimura S, Matsumoto M, Fujimoto K (2017) Persistent gastrointestinal angiodysplasia in Heyde's syndrome after aortic valve replacement. Intern Med 56(18): 2431-2433. https://doi.org/10.2169/internalmedicine.8603-16

56. Bon C, Aparicio T, Vincent M, Mavros M, Bejou B, Raynaud JJ, Zampeli E, Airinei G, Sautereau D, Benamouzig R, Michopoulos S (2012) Long-acting somatostatin analogues decrease blood transfusion requirements in patients with refractory gastrointestinal bleeding associated with angiodysplasia. Aliment Pharmacol Ther 36(6):587-593. https://doi.org/1 0.1111/apt. 12000

57. Ge Z-Z, Chen H-M, Gao Y-J et al (2011) Efficacy of thalidomide for refractory gastrointestinal bleeding from vascular malformation. Gastroenterology 141(5):1624-1629. https://doi.org/10.1053/j.gastro.2011.07.018

58. Junquera F, Feu F, Papo M, Videla S, Armengol JR, Bordas JM, Saperas E, Piqué JM, Malagelada JR (2001) A multicenter, randomized, clinical trial of hormonal therapy in the prevention of rebleeding from gastrointestinal angiodysplasia. Gastroenterology 121(5):1073-1079. https://doi.org/10.1053/ gast.2001.28650

59. Ohta S, Watanabe T, Morita S, Ueno S, Tsuji Y, Nakase H, Chiba T (2009) Massive jejunal bleeding due to Heyde syndrome successfully treated with double balloon endoscopy. Clin J Gastroenterol 2(3):187-189. https://doi. org/10.1007/s12328-009-0069-9

60. Olmos JA, Marcolongo M, Pogorelsky V, Herrera L, Tobal F, Dávolos JR (2006) Long-term outcome of argon plasma ablation therapy for bleeding in 100 consecutive patients with colonic angiodysplasia. Dis Colon Rectum 49(10):1507-1516. https://doi.org/10.1007/s10350-006-0684-1

61. Takahashi N, Tanabe K, Yoshitomi H et al (2010) Successful endoscopic clipping for bleeding from colonic angiodysplasia in a case of Heyde syndrome. Med Sci Monit Int Med J Exp Clin Res 16:CS107-CS109

62. Ladas S-D, Karamanolis G, Ben-Soussan E (2007) Colonic gas explosion during therapeutic colonoscopy with electrocautery. World J Gastroenterol 13(40):5295-5298. https://doi.org/10.3748/wjg.v13.i40.5295

63. Walker TG (2009) Acute gastrointestinal hemorrhage. Tech Vasc Interv Radiol 12(2):80-91. https://doi.org/10.1053/j.tvir.2009.08.002

64. Gifford SM, Peck MA, Reyes AM, Lundy JB (2012) Methylene blue enteric mapping for intraoperative localization in obscure small bowel hemorrhage: report of a new technique and literature review: combined intraoperative methylene blue mapping and enterectomy. J Gastrointest Surg 16(11):21772181. https://doi.org/10.1007/s11605-012-1964-9

65. de Leite TFO, Pereira OI (2019) Superselective transcatheter arterial embolization in the treatment of angiodysplasia. Clin Med Insights Case Rep 12:1179547619842581

66. Mirsadraee S, Tirukonda P, Nicholson A, Everett SM, McPherson SJ (2011) Embolization for non-variceal upper gastrointestinal tract haemorrhage: a systematic review. Clin Radiol 66(6):500-509. https://doi.org/10.1016/j.crad.2 010.11 .016

\section{Publisher's Note}

Springer Nature remains neutral with regard to jurisdictional claims in published maps and institutional affiliations. 